\title{
Efeito de alterações no preço de referência sobre as indenizações do Seguro Agrícola de Faturamento da soja no Brasil
}

\author{
Changes effect in the reference price on indemnities for soybean \\ Revenue Insurance in Brazil
}

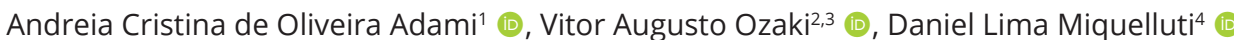

${ }^{1}$ Centro de Estudos Avançados em Economia Aplicada (CEPEA), Escola Superior de Agricultura "Luiz de Queiroz" (ESALQ), Universidade de São Paulo (USP), Piracicaba (SP), Brasil. E-mail: adami@cepea.org.br

¿Escola Superior de Agricultura "Luiz de Queiroz" (ESALQ), Universidade de São Paulo (USP), Programa de Pós-graduação em Economia Aplicada, Grupo Geser - Gestão em Seguros e Riscos, Piracicaba (SP), Brasil. E-mail: vitorozaki@usp.br 3Escola Superior de Agricultura "Luiz de Queiroz" (ESALQ), Universidade de São Paulo (USP), Programa de Pós-graduação em Estatística e Experimentação Agronômica, Grupo Geser - Gestão em Seguros e Riscos, Piracicaba (SP), Brasil. ${ }^{4}$ Grupo Geser - Gestão em Seguros e Riscos, Escola Superior de Agricultura "Luiz de Queiroz" (ESALQ), Universidade de São Paulo (USP), Piracicaba (SP), Brasil. E-mail: danielmiq@usp.br

\footnotetext{
Como citar: Adami, A. C. O., Ozaki, V. A., \& Miquelluti, D. L. (2022). Efeito de alterações no preço de referência sobre as indenizações do Seguro Agrícola de Faturamento da soja no Brasil. Revista de Economia e Sociologia Rural, 60(4), e247784. https://doi.org/10.1590/1806-9479.2021.247784
}

\begin{abstract}
Resumo: O seguro agrícola de faturamento possui vantagens e desvantagens frente ao seguro agrícola tradicional e, apesar de sua grande penetração no mercado norte-americano, no Brasil essa modalidade ainda é incipiente. Diante disso, o objetivo deste estudo foi avaliar o efeito de alterações no preço de referência (preço base) sobre as indenizações desses contratos para a cultura da soja, em municípios selecionados, no período de 2008 a 2018. Os resultados mostraram que há fraca associação entre as séries de preço e produtividade, pois o efeito estimado ficou próximo de zero, mas de caráter negativo em que preço e produção apresentam comportamento inversamente correlacionados. Além disso, a escolha do parâmetro de preços teve forte influência no valor da indenização, já que ao utilizar o preço de Paranaguá, os produtores receberiam um montante de indenização menor do que aquele a que teriam direito caso utilizassem o preço de referência da sua região. Em particular, para os estados do Mato Grosso e Mato Grosso do Sul, a diferença seria muito maior. Este fato pode ser um indício da baixa contratação do seguro de faturamento por esses produtores, que mesmo com a subvenção federal, têm apresentado demanda menor, comparativamente aos produtores da região Sul.
\end{abstract}

Palavras-chave: seguro agrícola de faturamento, seguro rural, risco de preço, risco de produtividade.

Abstract: Agricultural revenue insurance has advantages and disadvantages compared to traditional crop insurance and, despite its great penetration in the North American market, in Brazil, it is still incipient. The objective of this study was to evaluate the changes effect in the reference price (base price) on the indemnities of these contracts for the soybean crop, in selected municipalities, from 2008 to 2018. The results showed that there is a weak association between price and productivity since the estimated effect was close to zero, but it was negative in which price and production show an inversely correlated behavior. Also, the choice of the price parameter had a strong influence on the indemnity value. When using the Paranaguá price, producers would receive a lower amount of indemnity than if they used the reference price in their region. In particular, for the states of Mato Grosso and Mato Grosso do Sul the difference would be much greater. This fact may be an indication of the low contracting of income insurance by these producers, who, even with the federal subsidy, have shown less demand, compared to producers in the South region.

Keywords: income insurance, crop insurance, price risk, productivity risk.

\section{INTRODUÇÃO}

O agronegócio no Brasil responde por aproximadamente 25\% do Produto Interno Bruto (PIB) da economia brasileira e é responsável por quase metade do volume financeiro obtido 
com as exportações do país (Universidade de São Paulo, 2020). No entanto, apesar da elevada representatividade, a cadeia produtiva do agronegócio representada pela agropecuária possui diversos riscos que dificultam sobremaneira a estabilidade da renda do setor.

De acordo com o relatório do Banco Mundial em conjunto com a Embrapa (Empresa Brasileira de Pesquisa Agropecuária), denominado "Gestão de Riscos Agropecuários no Brasil: Caminhos para uma Visão Integrada", lançado em 2015, dentre uma multiplicidade de riscos enfrentados pelo setor, aquele que apresenta maior criticidade é a ocorrência de seca (Arias et al., 2015). A seca pode reduzir drasticamente a produção agrícola, trazendo efeitos perversos ao produtor rural. Do ponto de vista econômico, a perda de produção pode reduzir não apenas sua capacidade de honrar as dívidas com seus credores, mas principalmente o retorno de seu investimento.

Apesar da grande preocupação em se obter uma colheita volumosa, destaca-se outra variável de fundamental importância para o equacionamento financeiro dos produtores rurais: os preços. Analisados de forma isolada, as duas variáveis não dizem muito a respeito do faturamento obtido, ou seja, o preço multiplicado pela produção colhida. Nesse sentido, não se sabe ao certo o saldo líquido, em termos de faturamento, quando se observam apenas a produção ou os preços. Em outras palavras, uma elevada produção pode ser contrabalanceada por preços baixos, e vice-versa, reduzindo o ganho de faturamento pelo produtor (Duarte \& Ozaki, 2019).

Como estratégia de maximização do retorno, é interessante obter os maiores patamares de faturamento ao menor custo possível. Sob uma perspectiva alternativa, é preferível, em muitas situações, maximizar o retorno dado certo nível de risco aceitável. Usualmente, os produtores utilizam como estratégia para mitigação e transferência das consequências dos riscos dois instrumentos: derivativos agropecuários para garantir um nível adequado de preços e o seguro agrícola para cobrir perdas com produção (Ozaki, 2010).

Uma alternativa ao uso conjugado desses dois instrumentos é o seguro agrícola de faturamento. Diferentemente do seguro agrícola de custeio ou produtividade, o seguro de faturamento cobre ao mesmo tempo as perdas na produção agrícola, decorrentes de eventos climáticos adversos e quedas nos preços. No seguro de faturamento mais comercializado no país, a soja é a cultura que tem maior peso nas contratações, e seu preço de referência é a cotação de Paranaguá, já que a região Sul do país é uma região tradicional e referência para a liquidação dos contratos futuros negociados na Bolsa de Mercadorias e Futuros - B3 (Banco do Brasil, 2021).

No entanto, a partir dos anos 1990, a produção de soja avançou para o Centro-Oeste, que é hoje a principal região produtora. Ainda, nos anos 2000 a nova fronteira agrícola avançou rumo aos estados da região Norte, como Pará. Dessa forma, com a crescente participação de outros estados brasileiros na produção e comercialização da soja, faz-se necessário uma análise aprofundada do efeito dos valores comercializados nessas praças de referência alternativas, como Sorriso (MT), Dourados (MS) e Barreiras (BA), sobre a indenização paga aos produtores, já que a definição do preço a ser garantido torna-se um parâmetro relevante para o bom desempenho do seguro de faturamento. Entretanto, espera-se que, prevalecendo a lei do preço único, com consequente transmissão de preços entre as praças de produção/ comercialização do produto, estes apresentem comportamento semelhante em relação aos preços de Paranaguá e, portanto, riscos semelhantes. Caso essa hipótese seja comprovada, os preços dessas praças poderiam ser utilizados como referência para precificação do seguro de faturamento em diferentes regiões produtoras do país.

Nesse contexto, o objetivo deste trabalho foi verificar o efeito de alterações no preço de referência (preço base) sobre as indenizações do seguro de faturamento utilizado pelos produtores de soja (disponível no mercado) para os municípios selecionados (principais praças de comercialização da oleaginosa), no período de 2008 a 2018 (Universidade de São Paulo, 
2020). Em outras palavras, o estudo tenta responder à seguinte questão: caso a seguradora tenha a opção de usar preços de referência da praça de comercialização mais próxima ao produtor, qual seria o impacto no cálculo da indenização, em caso de sinistro?

Para tanto, o estudo está subdividido em mais 5 seções além desta introdução. A segunda seção apresenta a fundamentação teórica sobre o tema com uma breve evolução da política do seguro agrícola no Brasil e seu panorama atual, sobre os principais aspectos da formação e volatilidade dos preços da soja no país e da produção da oleaginosa nas principais regiões produtoras brasileiras. Na seção três, a metodologia é detalhada; na quatro, os principais resultados são apresentados e discutidos; na cinco, algumas considerações são apontadas; e na seis as referências citadas são detalhadas.

\section{FUNDAMENTAÇÃO TEÓRICA}

\subsection{Antecedentes do seguro agrícola e o panorama atual do seguro de faturamento}

Em 2003, o Governo Federal, através da Lei 10.823, criou o Programa de Subvenção ao Prêmio do Seguro Rural (PSR). O objetivo desse programa foi impulsionar o seguro rural no país e reduzir o prêmio do seguro pago pelos produtores rurais. A criação do PSR foi a primeira iniciativa de impacto do Ministério da Agricultura, Pecuária e Abastecimento (MAPA), por meio do Departamento de Gestão de Risco Rural (DEGER), no sentido de criar condições para o desenvolvimento do seguro rural no país. Apesar de a Lei 10.823 ter sido sancionada em 2003, sua regulamentação ocorreu apenas em 2004, por intermédio do Decreto 5.121.

Para o ano de 2005, os percentuais e os limites de subvenção foram determinados pelo Decreto 5.514/05. Nesse ano, as culturas cobertas pelo PSR foram algodão, arroz irrigado, feijão, milho (primeira e segunda safras), soja, trigo, maçã e uva. Os percentuais de subvenção variaram entre $30 \%$ e $50 \%$, dependendo da cultura, e o limite de apoio por produtor foi de $\mathrm{R} \$ 7.000,00$ para grãos e $\mathrm{R} \$ 12.000,00$ para as frutas. Em 2006, o Decreto 5.514/05 foi revogado pelo Decreto 5.782/06, que fixou novos limites e patamares de subvenção para aquele ano.

O novo decreto ainda incluiu novas culturas, como aveia, canola, centeio, cevada, sorgo e triticale, entre outras; além das modalidades: pecuária, florestal e aquícola. Neste mesmo ano, foi sancionado o Decreto 6.002, que fixou os percentuais de subvenção entre 30\% e 60\% para o triênio 2007 a 2009, e as culturas elegíveis ao PSR permaneceram as mesmas de 2006 para o triênio 2007/09, com a diferença de aumento do percentual de subvenção para os grupos que compõem as frutas para $50 \%$ e $40 \%$, respectivamente.

Ao longo do tempo, as regras mudaram substancialmente. Para o último triênio, 2019/2021, os percentuais foram ajustados, variando com o nível de cobertura e tipo de seguro (Tabela 1). Os valores máximos de subvenção ao prêmio do seguro rural, por beneficiário (pessoa física ou jurídica), em cada ano civil, foram estabelecidos em: Modalidade agrícola: $R \$ 72.000,00$; e Modalidades pecuário, florestal e aquícola: $\mathrm{R} \$ 24.000,00$ (para cada uma delas). Apesar dos limites fixados, o produtor pode receber a subvenção para mais de uma modalidade, desde que o somatório do benefício não ultrapasse o valor máximo de $R \$ 144.000,00$ por ano civil (Brasil, 2020b).

Existem oito modalidades para o seguro rural, mas apenas quatro delas compõem o PSR: agrícola, pecuário, aquícola e florestal. Para cada uma dessas modalidades, os planos trienais determinam os percentuais de subvenção para o período. 
Tabela 1 - Percentuais e limites de subvenção para o triênio 2019 a 2021.

\begin{tabular}{|c|c|c|c|}
\hline $\begin{array}{l}\text { Modalidade } \\
\text { de Seguro }\end{array}$ & Grupos de culturas & $\begin{array}{c}\text { Subvenção } \\
(\%)\end{array}$ & $\begin{array}{l}\text { Limite por } \\
\text { Produtor } \\
\text { (R\$) }\end{array}$ \\
\hline Agrícola & $\begin{array}{l}\text { abacate, abacaxi, abóbora, abobrinha, alface, } \\
\text { algodão, alho, ameixa, amendoim, arroz, } \\
\text { atemoia, aveia, banana, batata, berinjela, } \\
\text { beterraba, cacau, café, caju, cana-de-açúcar, } \\
\text { canola, caqui, cebola, cenoura, cevada, centeio, } \\
\text { cherimoia, chuchu, couve-flor, ervilha, escarola } \\
\text { (chicória), fava, feijão, figo, girassol, goiaba, } \\
\text { graviola, jiló, kiwi, laranja, lichia, lima, limão e } \\
\text { demais cítricos, linho, maçã, mamão, mamona, } \\
\text { mandioca, manga, maracujá, melancia, melão, } \\
\text { milho, milho segunda safra, morango, nectarina, } \\
\text { pepino, pera, pêssego, pimentão, pinha, quiabo, } \\
\text { repolho, sisal, soja, sorgo, tangerina, tomate, trigo } \\
\text { triticale, uva, vagem e demais hortaliças e legumes. }\end{array}$ & $20-40^{*}$ & 48.000 \\
\hline Pecuário & $\begin{array}{l}\text { aves, bovinos, bubalinos, caprinos, equinos, } \\
\text { ovinos e suínos }\end{array}$ & - & 24.000 \\
\hline Florestal & silvicultura & 40 & \\
\hline Aquícola & carcinicultura, maricultura e piscicultura & - & \\
\hline
\end{tabular}

*De acordo com o nível de cobertura e tipo de seguro. Fonte: Brasil (2020b)

A Tabela 2 resume os resultados do PSR, de 2005 a 2018. Percebe-se o forte crescimento em todos os indicadores analisados durante quase todo o período, havendo, porém, uma redução no triênio 2016-2018. Esse crescimento foi possível em razão do aumento dos recursos públicos alocados ao PSR, que sofreram redução no último triênio em análise. Mesmo assim, verifica-se que os recursos utilizados pelo mercado aumentaram de $\mathrm{R} \$ 2,3$ milhões, em 2005, para um montante superior a 1,1 bilhão de reais no triênio 2016-2018.

Tabela 2 - Resultados do PSR - de 2005 a 2020, por triênio a partir de 2007.

\begin{tabular}{ccccccc} 
Ano & $\begin{array}{c}\text { Número } \\
\text { de apólices }\end{array}$ & $\begin{array}{c}\text { Número } \\
\text { de } \\
\text { produtores }\end{array}$ & $\begin{array}{c}\text { Subvenção } \\
\text { (R\$ } \mathbf{~ m i ) ~}\end{array}$ & $\begin{array}{c}\text { Área } \\
\text { segurada } \\
\text { (mi ha) }\end{array}$ & $\begin{array}{c}\text { Capital } \\
\text { segurado } \\
\text { (R\$ bi) }\end{array}$ & $\begin{array}{c}\text { Prêmio } \\
\text { arrecadado } \\
\text { (R\$ mi) }\end{array}$ \\
\hline 2005 & 849 & 849 & 2,30 & 0,07 & 0,13 & 8,70 \\
2006 & 21.783 & 16.460 & 31,10 & 1,76 & 2,87 & 69,96 \\
2007 a 2009 & 164.089 & 116.566 & 476,10 & 13,55 & 19,36 & 916,67 \\
2010 a 2012 & 172.644 & 121.445 & 764,30 & 14,43 & 22,47 & 1382,64 \\
2013 a 2015 & 259.167 & 166.667 & 1522,40 & 22,35 & 40,74 & 2689,87 \\
2016 a 2018 & 204.014 & 134.594 & 1116,50 & 14,84 & 37,36 & 2611,66 \\
Total & 1.109 .124 & 674.146 & 5221,57 & 87,38 & 188,30 & 11800,30 \\
\hline
\end{tabular}

Fonte: Brasil (2020c) . Nota: Até o momento, o MAPA não iniciou o recebimento de propostas no sistema, por questões orçamentárias. 
Os recursos utilizados no PSR provêm em sua totalidade do orçamento da União. Nesse sentido, a Figura 1 mostra a evolução do volume de recursos disponibilizados versus o volume de recursos executado, de 2005 a 2020. Percebe-se que tanto os recursos alocados (recurso liberado) ao PSR quanto os gastos efetivos (valor executado) cresceram, ainda que com algumas retrações pontuais, desde 2005 até 2013. A partir deste ano, observa-se certa estabilidade no montante alocado, sendo a exceção o anúncio recorde do volume de $R \$ 1$ bilhão para subvenção no ano de 2020, dos quais $\mathrm{R} \$ 881$ milhões foram de fato executados. Vale ressaltar que esse volume orçamentário é utilizado para todos os produtos (modalidades) de seguros existentes atualmente, ou seja, o seguro agrícola de custeio, o seguro agrícola de produtividade e o seguro agrícola de faturamento.

Este último foi desenvolvido recentemente por uma companhia seguradora privada e tem como público-alvo a cultura da soja (Brisolara, 2013). Neste tipo de seguro são cobertas reduções tanto na produtividade quanto no preço da saca, garantindo-se assim o faturamento da propriedade rural.

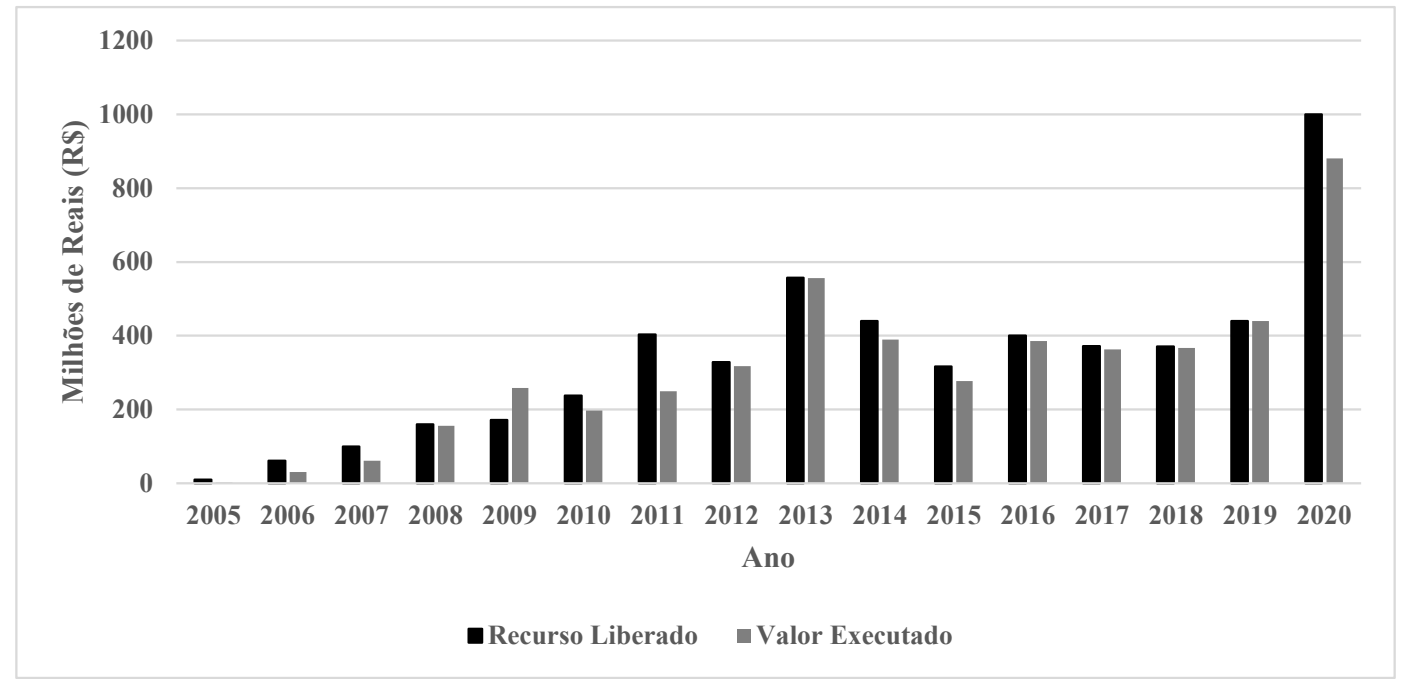

Figura 1 - Evolução dos recursos liberados e gastos efetivos, no período de 2005 a 2020, em milhões de reais. Fonte: Brasil (2020d)

O faturamento garantido em uma determinada operação de seguro de faturamento agrícola é obtido pela multiplicação do faturamento esperado por um nível de cobertura contratado. $O$ faturamento esperado é determinado pela multiplicação do preço base, definido na apólice pela seguradora, pela produtividade esperada, também definida na apólice. O nível de cobertura é escolhido na contratação e representa um percentual do faturamento esperado que se deseja proteger, comumente variando de $65 \%$ a $80 \%$. A descrição do cálculo de todos os parâmetros do seguro de faturamento e a relação entre eles conta da seção de metodologia abaixo.

O seguro de faturamento foi lançado em 2010 como um projeto-piloto e arrecadou em prêmios a quantia de $\mathrm{R} \$ 126$ mil, perfazendo $0,04 \%$ do total de prêmio obtido pelas seguradoras nas modalidades de seguro rural, ou do ramo agrícola. Embora não tenha atingido ainda os níveis de participação que tem nos Estados Unidos da América (EUA), ou seja, quase $90 \%$ do total (United States Department of Agriculture, 2020), o seguro faturamento correspondeu por 8,79\% do total de prêmio do ramo agrícola em 2019, com um valor total de aproximadamente $R \$ 81$ milhões em prêmios (Tabela 3). Uma análise mais consistente do seguro de faturamento deve ser realizada nos últimos cinco anos, em função de um direcionamento mais claro por parte 
do Governo Federal em alocar recursos orçamentários garantidos para esse tipo de produto. Nesse sentido, com exceção do ano de 2020, a média de apólices contratadas, importância segurada e subvenção foram iguais a 1.945; $R \$ 1$, 4 bilhão; e $R \$ 25,7$ milhões, respectivamente.

Tabela 3: Número de apólices, área total, importância segurada, prêmio total, volume de subvenção do seguro de faturamento, no período de 2010 a 2020.

\begin{tabular}{cccccc} 
Ano & Apólices & $\begin{array}{c}\text { Área } \\
\text { (ha) }\end{array}$ & $\begin{array}{c}\text { Importância } \\
\text { Segurada (R\$) }\end{array}$ & $\begin{array}{c}\text { Prêmio } \\
\text { (R\$) }\end{array}$ & $\begin{array}{c}\text { Subvenção } \\
\text { (R\$) }\end{array}$ \\
\hline 2010 & 8 & 1.506 & 4.315 .239 & 126.499 & 63.249 \\
2011 & 225 & 31.345 & 65.300 .642 & 3.671 .979 & 1.835 .990 \\
2012 & 148 & 19.709 & 77.353 .063 & 4.010 .268 & 2.312 .079 \\
2013 & 1.905 & 284.293 & 692.459 .595 & 39.275 .838 & 20.421 .030 \\
2014 & 2.613 & 408.862 & 999.111 .832 & 66.241 .818 & 35.221 .373 \\
2015 & 340 & 45.803 & 150.555 .136 & 8.371 .897 & 4.458 .804 \\
2016 & 1.679 & 336.668 & 1.037 .336 .562 & 48.196 .160 & 18.536 .748 \\
2017 & 1.681 & 346.493 & 1.013 .015 .034 & 46.757 .058 & 17.913 .639 \\
2018 & 2.353 & 583.472 & 1.927 .697 .186 & 87.887 .438 & 34.459 .488 \\
2019 & 2.067 & 447.299 & 1.708 .245 .227 & 80.595 .199 & 31.918 .480 \\
2020 & 10.976 & 1.340 .248 & 6.474 .945 .387 & 343.629 .635 & 103.754 .814 \\
\hline
\end{tabular}

Fonte: Brasil (2020d)

A partir de 2012, uma segunda companhia seguradora passou a ofertar o seguro de faturamento, com pequenas diferenças na definição do preço tanto de contratação quanto de colheita. Atualmente, apenas duas companhias oferecem o produto. Desde 2010, os três estados que mais contrataram o seguro de faturamento foram, respectivamente, Goiás, Mato Grosso do Sul e Paraná, que juntos responderam por quase $65 \%$ da área total contratada. Ademais, dentre as culturas que são contempladas com o seguro de faturamento, ou seja, soja, milho (1 a e 2a safras) e café, a soja corresponde a quase 100\% das operações (Brasil, 2020d).

A literatura nacional acerca do tema ainda é restrita. Destacam-se as contribuições de Miqueleto (2011) e Brisolara (2013). Os trabalhos exploram os produtos de seguro faturamento adotados nos Estados Unidos e Canadá, trazendo recomendações sobre modelos de produtos que poderiam ser implementados no Brasil. Em ambos os trabalhos, também foram calculadas as taxas de prêmio, de modo a trazer valores de referência para as seguradoras, e mostrando a superestimação ou subestimação dos produtos comercializados à época.

Recentemente, Adami \& Ozaki (2016) verificaram a viabilidade de um seguro de receita para soja na região oeste do Paraná, sob o ponto de vista das seguradoras. Mostraram que o produto de seguro faturamento tem potencial de gerar retornos financeiros atrativos para as seguradoras, sendo assim recomendado para a região e cultura em estudo. No entanto, os autores apontam que as taxas empíricas calculadas pelas seguradoras subestimaram o risco para níveis de cobertura de $50 \%$ e $60 \%$, mas foram compatíveis ao nível de cobertura de $70 \%$.

\subsection{Formação e volatilidade dos preços da soja no Brasil}

O comportamento dos preços da soja no mercado brasileiro pode ser afetado tanto por eventos internos quanto externos. Alguns trabalhos apresentados na literatura apontam que o Brasil, apesar de ser um grande produtor, está entre os maiores produtores mundiais, e da importância do complexo da soja para o agronegócio nacional, os preços da oleaginosa são determinados no mercado internacional, pelas condições da oferta e demanda mundial pelo produto (Sousa \& Margarido, 1998; Mafioletti, 2001; Moraes, 2002; Ikeda, 2015). 
Assim, o país não é um formador do preço desse produto e, sim, um tomador de preços, como a maioria das commodities agrícolas. Desse modo, a formação de preços da soja em grão ocorre no mercado internacional de acordo com as tendências refletidas nas cotações da Bolsa de Chicago (CME/CBOT). E, diante da informação do preço atribuído ao grão na Bolsa de Chicago, os valores praticados internamente, pelos produtores nos diversos municípios brasileiros, seguem a cotação do mercado externo, cuja cotação de preço é dada em dólar americano.

Nesse sentido, a decisão do produtor brasileiro no momento da comercialização, quanto ao preço da soja a ser negociado, leva em conta, além da referência dos preços cotados na CBOT, também as ofertas de preços pagos pelos corretores, indústria esmagadora local, traders de importação e exportação, cooperativas e compradores de produtos agropecuários, seja na comercialização à vista, por meio da cédula do produto rural (CPR) ou contratos a termo.

Em termos de formação dos preços internos, Mafioletti (2001) aponta que, a partir do nível de preços negociado na Bolsa de Chicago (CBOT), incorporando-se o prêmio, ter-se-á o preço da soja nos portos brasileiros (FOB - Free on Board). A partir do preço FOB, deduzindo-se os custos portuários, fretes e outros custos de transação, chega-se ao preço na processadora, e, a partir desse preço, deduzindo-se ainda os custos operacionais, entre outros, obtém-se o preço de mercado em cada região ou município produtor (Moraes, 2002).

No Brasil, o preço da soja em Paranaguá, importante porto de escoamento da oleaginosa, tornou-se referência para a liquidação financeira do contrato futuro de soja na Bolsa de Mercadorias e Futuros (B3). Espera-se que, prevalecendo a Lei do Preço Único, o preço de uma mesma mercadoria, em diferentes países (regiões), quando cotado na mesma moeda e desconsiderando-se os custos de transferência e transação, deve ser igual.

Assim, o preço da soja nas diferentes regiões produtoras deve diferir pelo custo de transporte, ou carregamento da mercadoria, entre essas regiões e o porto de referência. Considerandose a integração entre esses mercados, do mesmo produto, mas separados geograficamente (espacialmente), deve haver influência de um mercado sobre o outro, ocorrendo transmissão de preços entre eles.

Portanto, espera-se que, a partir do preço do porto, os preços das regiões produtoras/ comercializadoras devem seguir comportamento semelhante ao longo do tempo, uma vez que as séries de preços de uma mesma mercadoria em diferentes regiões produtoras são cointegradas (Enders, 2008), ou seja, seguem um mesmo caminho de longo prazo, com variações (variabilidade) semelhantes e as diferenças em seus níveis devidas aos custos de transporte e transação, para entrega em Paranaguá.

Há na literatura brasileira trabalhos que estudaram a transmissão dos preços internacionais da soja para os preços na bolsa brasileira e entre diferentes níveis de mercado (Margarido et al., 2001; Waquil \& Dalla Libera, 2009; Presotto et al., 2019). No entanto, não há na literatura análises para o conjunto de informações sobre os preços utilizados neste trabalho. Dessa forma, a cointegração entre os mercados foi testada utilizando-se o teste de Johansen (Enders, 2008), uma vez que a integração entre os mercados e consequente transmissão das variações de preços entre eles é informação relevante para entendimento do risco de preço.

\subsection{Aspectos da produção da soja no Brasil}

Comparativamente a outros países, o Brasil ocupa lugar de destaque no mercado mundial de soja. Em 2019, de acordo com dados do Brasil (2020a), o país foi o segundo maior produtor e maior exportador de soja em grão. O país tem se mantido como segundo maior produtor do grão desde início dos anos 2000, logo após os EUA (Food and Agriculture Organization of 
the United Nations, 2020). A China, por sua vez, possui pequena participação na produção mundial, mas é o principal país consumidor da oleaginosa. Juntos, EUA, Brasil, Argentina e China têm produzido aproximadamente $85 \%$ da produção mundial de soja (Food and Agriculture Organization of the United Nations, 2020).

No Brasil, os principais estados produtores são Mato Grosso (MT), Paraná (PR), Rio Grande do Sul (RS) e Goiás (GO). Informações da Companhia Nacional de Abastecimento - CONAB (Brasil, 2019) mostram que, desde a safra 2008/2009, Mato Grosso, Paraná e Goiás têm aumentado sua participação na produção nacional, e na safra 2019/2020 estima-se que a participação desses três estados fique em torno de $53 \%$ da produção brasileira.

O Paraná, segundo maior produtor brasileiro, tem participação esperada de $16 \%$ na safra 2019/2020. O estado apresentou produção crescente nas últimas doze safras (2008/2009 a 2019/2020), com exceção da safra 2011/2012, pois nesta safra o Paraná sofreu redução forte devido à grave seca que ocorreu no Sul do país. Ressalta-se que, em termos de produção, os estados da região Sul apresentam riscos relativamente mais elevados do que o estado do Mato Grosso, em razão principalmente do clima mais adverso. A produção de soja no estado de Mato Grosso apresenta tendência de crescimento sem maiores quedas, nesse mesmo período, com exceção da safra 2015/16, ano em que houve uma quebra significativa na produção, em função da grave seca (Brasil, 2019).

Uma implicação direta desse fato é o maior interesse e demanda por seguro agrícola nos municípios localizados na região Sul. A atividade foi destino de quase $48 \%$ dos recursos alocados ao PSR em 2019, o que representou quase $90 \%$ das contratações feitas pelas culturas de verão (Brasil, 2020b).

Por ser um dos estados brasileiros que mais sofrem com perda de safra por problemas climáticos, os produtores do estado do Paraná são os que mais recorrem ao PSR. Em 2019, o estado ficou com $29,5 \%$ do total dos recursos da subvenção, sendo que desse total, a soja correspondeu a 49,2\%. Por outro lado, os produtores de soja do estado de Mato Grosso, principal produtor brasileiro, apresentaram participação de apenas $6,5 \%$ em toda subvenção destinada para a soja brasileira em 2019 (Brasil, 2020b).

Os estados da região Centro-oeste têm sofrido danos relativamente menores à produção por eventos climáticos adversos. Por outro lado, a volatilidade (variabilidade) dos preços recebidos pelos produtores tem se apresentado elevada, principalmente nos últimos anos, devido às crises nacionais e internacionais.

O resultado, em termos de faturamento, quando se observa a interação entre as variáveis preço e produção, torna-se incerto e pode variar dependendo da região produtora. Desse modo, uma análise da função faturamento para os principais estados produtores torna-se relevante, pois pode trazer luz a aspectos importantes para o desenho do seguro faturamento, o que faz com que esses seguros possam ser aprimorados e desempenhem de forma ótima seu papel na proteção da atividade.

\section{METODOLOGIA}

\subsection{Dados}

Os dados de preços utilizados neste trabalho foram coletados pelo CEPEA (Universidade de São Paulo, 2020). O Indicador da soja Paranaguá (Universidade de São Paulo, 2020) refere-se ao grão comercializado na condição de transferido para armazéns ou silos portuários situados no corredor de exportação do porto de Paranaguá. Os preços foram obtidos da consulta a 
produtores, cooperativas, indústrias e produtores de aves e suínos, indústrias de alimentos, indústrias de ração, cerealistas, empresas comerciais exportadoras (trading companies) e corretores, que são consultados diariamente na praça de comercialização, os quais participam das transações nas condições de comprador, vendedor ou intermediário entre as partes.

No caso dos Indicadores regionais, foram consideradas as seguintes praças de referência: Indicador de preços Paraná, para o estado do Paraná; praça de Dourados, como preço representativo do estado de Mato Grosso do Sul; Barreiras, na Bahia; ljuí para o Rio Grande do Sul, Mogiana para São Paulo; e Sorriso para Mato Grosso.

Os valores dos indicadores se referem aos preços de negócios no mercado de lotes (entre empresas), a retirar na empresa/armazém de venda. Os preços dessas praças foram considerados representativos dos estados em questão para o cálculo do faturamento garantido, pois trata-se dos municípios em que há maior concentração de negócios nessas regiões. No caso do Indicador do Paraná, o estado do Paraná está dividido em cinco regiões: Paranaguá, Ponta Grossa, Norte, Oeste e Sudoeste, conforme definido em Cepea (Universidade de São Paulo, 2020).

Foram coletados preços diários da saca de 60 quilos $(\mathrm{kg})$, dos quais foram obtidas as médias mensais para as regiões produtoras, como também para o preço de referência, Paranaguá. Os preços foram deflacionados pelo Índice Geral de Preços Disponibilidade Interna - IGP-DI da Fundação Getúlio Vargas para reais de março de 2020.

No caso dos dados de área, produção e produtividade, estes foram obtidos por meio do Levantamento Sistemático da Produção Agrícola e da Produção Agrícola Municipal, ambos do Instituto Brasileiro de Geografia e Estatística (2020). Os dados da produção agrícola estão sujeitos a mudanças nas práticas e na tecnologia, que não são de interesse para este estudo, portanto, procedeu-se à detecção e remoção de tendência na série de produção. Primeiramente foi realizado o teste de Dickey-Fuller Aumentado, de modo a verificar a não estacionariedade das séries, sendo posteriormente ajustada uma regressão linear, tendo o tempo como variável explicativa (Gallagher, 1987; Duarte et al., 2018). A série com remoção de tendência é definida pela Equação 1:

$\widetilde{y_{t}}=\widehat{y_{T}}\left(1+\frac{\widehat{e_{t}}}{\widehat{y_{t}}}\right)$

onde $\widetilde{y_{t}}, \widehat{y_{t}}$ e $\widehat{e_{t}}$ são, respectivamente, a produção corrigida, a produção ajustada e o resíduo para o ano $t, \widehat{y_{T}}$ é a produção ajustada para o último ano da série.

\subsection{Seguro Agrícola de Faturamento: fundamentos estatísticos}

Nesta subseção estão descritas as fórmulas de cálculo e os parâmetros utilizados no seguro faturamento objeto de estudo desta pesquisa. O principal desafio no desenho do seguro de faturamento (receita) agrícola é a definição da produtividade esperada e do preço a ser garantido. Como o seguro é negociado antes do período de plantio e o período de apuração do sinistro, caso ocorra, no período de colheita, o preço é fixado com base em expectativas na entressafra do preço a vigorar na safra.

A produtividade esperada, por sua vez, é definida com base no histórico das produtividades observadas nos anos anteriores ao ano de fechamento do contrato. Assim, o faturamento esperado (FAE) é calculado considerando um preço base (PB) da saca de 60 quilos de soja, definido de acordo com uma referência de cotação para seu preço futuro; a produtividade esperada (PE) em sacas de 60 quilos por hectare, que é definida com base no histórico dos últimos cinco anos da produtividade por hectare (ha); e a área total a ser segurada (AS), que se 
refere ao tamanho da área com soja da propriedade a ser segurada em hectares. O FAE pode também sofrer um deságio (D), em percentual (\%), que deve ser negociado entre a empresa seguradora e o produtor. Equação 2:

$F A E=P B * P E * A S * D \#$

Ainda, o FAE pode ter seu valor ajustado a qualquer momento, nos casos em que o produtor não respeite as diretrizes definidas pelo MAPA no Zoneamento Agrícola de Risco Climático (ZARC) e o plantio seja realizado no período de risco. Caso isso ocorra, é aplicado o Fator Plantio (FP). Nestes casos poderão ser aplicados FP de redução de $10 \%$ até $20 \%$ sobre a PE em caso de sinistro. Assim, o Faturamento Esperado Ajustado (FAEA) pode ser calculado de acordo com a Equação 3:

$F A E A=P B^{*} P E^{*} A S^{*} D *(1-F P) \#$

Após definidas as cláusulas do Seguro de Faturamento Agrícola, que estabelecem o FAEA, o Faturamento Garantido (FAG) ao produtor, em caso de sinistro, se refere à parcela do faturamento esperado ajustado (FAEA), considerando também o nível de cobertura (CoB) escolhido pelo produtor. O produtor rural poderá escolher um nível de cobertura (a) entre $60 \%$ e $85 \%$, de acordo com os níveis ofertados pela seguradora. Assim, o faturamento garantido será dado por - Equação 4:

$F A G=F A E A^{*} \alpha \#$

O produtor rural tem direito a receber a indenização quando o faturamento obtido (FAO) ou efetivo (que ocorre na safra) se situar abaixo do faturamento garantido (FAG), sendo a indenização calculada pela diferença entre os dois. O FAO depende da produtividade obtida (PO) na safra e preços de mercado à época da colheita, preço de colheita (PC). O PC, em reais por saca de 60 quilos, é calculado por meio da média das últimas 15 cotações de preços diários da soja do Indicador de preço disponível (Universidade de São Paulo, 2020), disponibilizado pela Bolsa de Mercadorias e Futuros (BM\&FBovespa - B3), anteriores à data de execução do seguro, e que são convertidos em reais pela PTAX800, cotação de venda diária, em real por dólar americano (R\$/US\$), cujos valores devem ser coletados para o mesmo período de referência dos preços da soja - Equação 5.

$F A O=P O * P C * A S \#$

$\mathrm{Na}$ Equação 5, que representa a função FAO, preço de colheita (PC) e produtividade obtida (PO), no momento da contratação do seguro, são variáveis desconhecidas e consideradas aleatórias. Já a área segurada (AS) é uma constante que foi fixada no momento da definição do contrato. Considerando o faturamento obtido por unidade de área (hectare), pode-se deduzir as relações estatísticas entre as duas variáveis, de acordo com Mood et al. (1974), a esperança matemática do FAO fica - Equação 6:

$$
E[F A O]=A S^{*} E[P C P O]=A S^{*} E[P C] E[P O]+C O V(P C, P O) \#
$$

Observa-se da Equação 6 que a esperança matemática de uma função multiplicativa não é simplesmente a multiplicação da esperança matemática de cada variável aleatória, no caso das variáveis aleatórias não serem independentes. Neste caso deve-se considerar também a covariância (COV) entre as duas variáveis aleatórias, ou seja, o movimento conjunto entre elas. A função de covariância pode ser definida como o produto do coeficiente de correlação 
entre as duas variáveis e seus respectivos desvios-padrão: $\operatorname{COV}(P C, P O)=\rho(P C P O) \sigma(P C) \sigma(P O)$, com $\rho(P C P O)$ representando o coeficiente de correlação entre preço (PC) e produtividade (PO), $\sigma(P C)$ o desvio-padrão da série de preços, e $\sigma(P O)$ o desvio-padrão da série de produtividade.

Ainda, a variância teórica é uma das principais medidas de dispersão ou variabilidade (em torno da esperança matemática) de uma variável aleatória. Sabe-se da Lei dos grandes números que a variância amostral converge para a variância teórica, na medida em que o número de observações cresce. A função variância (VAR) entre preço (PC) e produtividade (PO) pode ser definida como (Mood et al., 1974) - Equação 7:

$\operatorname{VAR}[F A O]=A S^{2} \operatorname{VAR}[P C P O]=A S^{2} *\left\{E^{2}[P C] * \operatorname{VAR}[P O]+E^{2}[P O] * \operatorname{VAR}[P C]+2 * E[P O] * E[P C]^{*} \operatorname{COV}(P O P C)\right\}(7)$

E, dessa forma, a correlação entre as variáveis definirá o impacto da covariância sobre a variabilidade do FAO por hectare. Se as duas variáveis apresentam correlação nula, a COV não impactará na variabilidade do FAO, mas se preço e produtividade forem negativamente correlacionados, perdas de produção devem ser compensadas por ganhos de preço, impactando em menor queda de faturamento ou menor variabilidade (risco) do FAO.

A correlação entre as séries foi medida pelo coeficiente de correlação de Pearson no caso de variáveis com distribuição normal, ou pelo Tau de Kendall, nos casos em que o teste de Shapiro-Wilk tenha indicado desvio de normalidade. Além disso, o coeficiente de variação, que é calculado pelo desvio-padrão da variável aleatória dividida pela sua média, foi utilizado como medida de risco relativo neste trabalho.

É importante frisar que se espera que a produtividade de cada produtor individualmente não tenha impacto significativo sobre os preços de mercado, e, desse modo, preço e produtividade seriam variáveis independentes. No entanto, pela característica sistêmica do risco climático, pode haver algum efeito, caso a perda se dê em grande magnitude, gerando uma significativa quebra de safra no cenário nacional e/ou internacional. Esse efeito, se houver, deve ser capturado pela correlação entre as variáveis.

Após diagnóstico inicial, e de modo a verificar se a utilização de preços regionais impacta significativamente o desempenho do seguro de faturamento, foi conduzida a comparação do faturamento médio considerando-se o preço de venda de cada praça produtora e o preço do indicador da Soja BM\&F/Bovespa (B3). Similarmente ao procedimento efetuado no caso da correlação, a normalidade das séries também foi testada a partir do teste de Wilcoxon para a comparação de médias.

Finalmente, foram simulados contratos de seguro faturamento para um nível de cobertura de $85 \%$ para os anos de 2008 a 2018 nos municípios em que as informações coletadas estavam disponíveis desde o ano de $2002^{1}$. Como os dados de produtividade utilizados consistem em médias municipais, não se pode calcular de modo exato o preço esperado e o preço de colheita, desse modo, ambos foram calculados como a média dos preços de cada praça e o indicador da soja para os meses de plantio e de colheita, conforme calendário divulgado pela CONAB (Brasil, 2019).

Novamente, a ideia desta análise é também comparar o desempenho destes contratos utilizando-se os preços das praças em relação ao indicador da soja da B3, para tanto os resultados desta simulação foram apresentados em termos de diferença percentual do total acumulado de indenizações no período em análise.

${ }^{1}$ Isto é necessário para calcular a produtividade esperada por meio da média dos últimos 5 anos de produtividade. 


\section{RESULTADOS E DISCUSSÃO}

Nesta seção, as séries de preços, produtividade e faturamento de cada praça são apresentados, além das medidas de risco calculadas e os valores de indenização estimados. O objetivo da análise foi verificar se há diferença no risco associado às séries que afetam o resultado do seguro de faturamento e no valor da indenização, caso os preços regionais fossem utilizados no contrato.

Os resultados do teste de cointegração de Johansen (Enders, 2008), apresentados na Tabela 4, mostram que as séries de preços são cointegradas, e desse modo seguem um mesmo caminho de longo prazo, conforme preconizado pela lei do preço único, confirmando assim a hipótese de que os mercados são integrados. O teste de cointegração de Johansen foi aplicado às séries de preços reais (deflacionados pelo IGP-DI) após verificada a ordem de integração destas através do teste ADF, que indicou que todas as séries são integradas de ordem um, I(1).

Tabela 4 - Resultados do teste de cointegração de Johansen para as séries de preços reais

\begin{tabular}{cccc}
$\begin{array}{c}\text { Vetor de } \\
\text { cointegração }-\boldsymbol{r}\end{array}$ & Estatística máximo & $\begin{array}{c}\text { Nível de confiança } \\
\mathbf{- 5 \%}\end{array}$ & $\begin{array}{c}\text { Nível de confiança } \\
\mathbf{- 1} \%\end{array}$ \\
$<=5$ & 9,56 & 8,18 & 11,65 \\
$<=4$ & 13,38 & 14,90 & 19,19 \\
$<=3$ & 19,36 & 21,07 & 25,75 \\
$<=2$ & 33,08 & 27,14 & 32,14 \\
$<=1$ & 46,42 & 33,32 & 38,78 \\
$=0$ & 53,21 & 39,43 & 44,59 \\
\hline
\end{tabular}

Fonte: Elaborado pelos autores a partir dos resultados da pesquisa.

O teste de cointegração de Johansen se baseia no posto da matriz de variáveis do sistema e suas raízes características. Quando não há combinações lineares das variáveis que sejam estacionárias, o posto da matriz é 0 , e não há relações de longo prazo entre as variáveis; quando o número de raízes características estatisticamente significativas for maior que zero e menor que $n$ (número de variáveis do sistema), haverá $r$ relações de longo prazo entre as variáveis $(0<r<n)$, e as mesmas são integradas.

Em relação aos preços nominais praticados nas principais regiões produtoras, ou praça de comercialização de referência, é possível verificar pelos dados da Figura 2 que, de fato, esses preços seguem comportamento semelhante, seguindo dessa forma o que preconiza a lei do preço único. Os coeficientes de correlação foram calculados para as praças duas a duas, e todos os valores foram bem elevados, ficando próximo a 0,99. Além disso, o coeficiente de variação das séries nominais, que é uma medida do risco relativo, também ficou próximo a 0,26 para todas as séries pesquisadas, o que mostra que todas as séries apresentam risco de preço semelhante.

Observa-se também que os valores apurados seguem tendência de alta no período avaliado, janeiro de 2007 a março de 2020. As séries mostram maior estabilidade entre os anos de 2007 e 2011. A partir de 2012, contudo, é possível verificar que as altas e quedas dos preços se intensificaram e há forte tendência de alta no período, pois as médias anuais dos preços de 2019 mais que dobraram em todas as regiões pesquisadas em relação aos valores médios do ano de 2007 (Figura 2). 


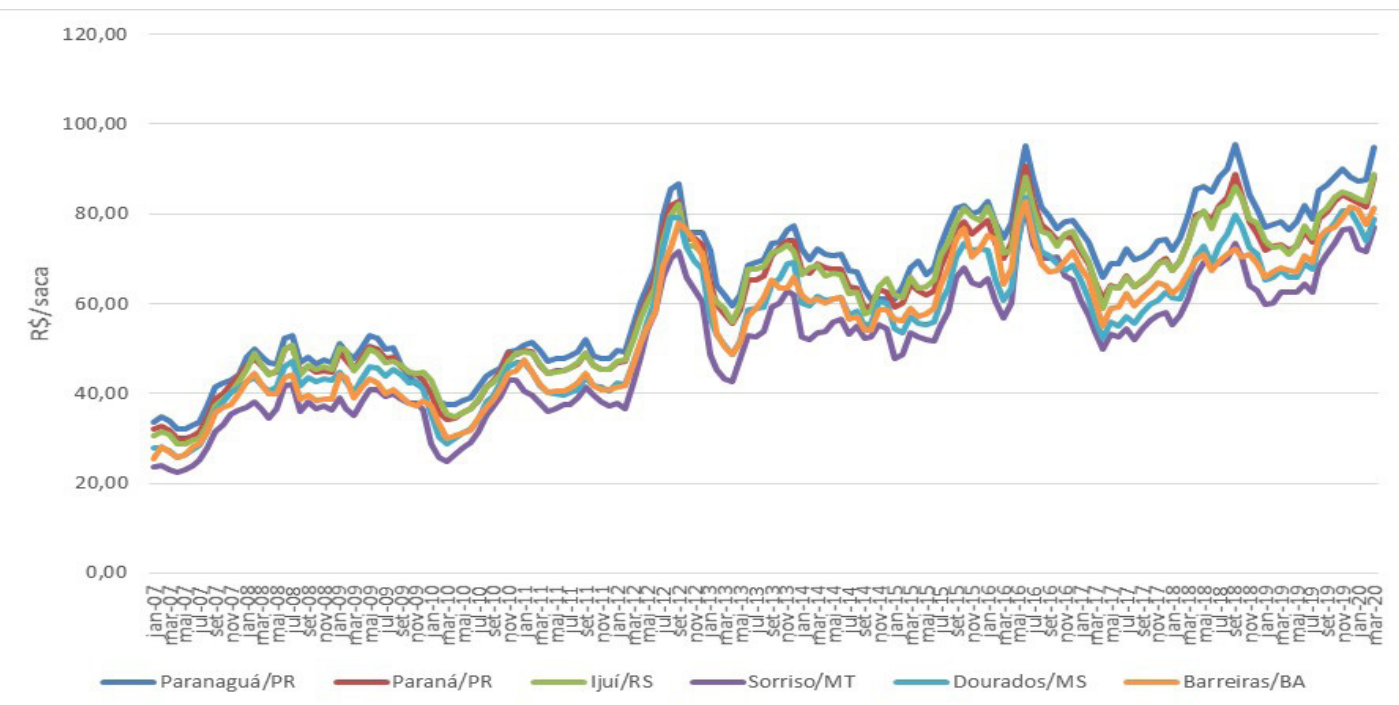

Figura 2 - Preços nominais da soja brasileira nas principais praças de referência, cotação mensal de janeiro de 2007 a março de 2020, em reais por saca de 60 quilos - R\$/saca. Fonte: Universidade de São Paulo (2020)

Os preços reais (deflacionados) e as séries de produtividade de cada estado foram testadas para a presença de raiz unitária (estacionariedade). Os resultados para os testes de estacionariedade da série de produtividade e normalidade para as séries de faturamento por hectare indicam a necessidade de remoção de tendência para os estados do Rio Grande do Sul e Mato Grosso. Pelo fato de a maioria dos estados apresentarem fuga de normalidade para a série de faturamento, optou-se pelo uso do Tau de Kendall para medir o grau de associação entre as séries e do teste de Wilcoxon para verificar diferenças entre as médias (Tabela 5).

Tabela 5 - p-valores para os testes de estacionariedade para a série de produtividade e de normalidade para o faturamento, por estado.

\begin{tabular}{ccr} 
UF & \multicolumn{1}{c}{$\begin{array}{c}\text { Estacionariedade } \\
\text { (Produtividade) }\end{array}$} & Normalidade (Faturamento) \\
\cline { 2 - 3 } & 0,0467 & p-valor \\
Bahia & 0,4500 & 0,0205 \\
Mato Grosso & 0,0100 & $<0,0100$ \\
Mato Grosso do Sul & 0,0100 & 0,2230 \\
Paraná & 0,0522 & 0,0871 \\
Rio Grande do Sul & 0,0245 & $<0,0100$ \\
São Paulo & 0,3080 \\
\hline
\end{tabular}

Fonte: Calculado pelos autores a partir dos dados da pesquisa.

Apresenta-se na Tabela 6 o Faturamento Médio calculado para os estados pesquisados, em milhões de reais $(R \$)$, a partir dos preços reais das praças de referência e do preço de Paranaguá, todos deflacionados. Observa-se que o faturamento calculado a partir dos preços do porto são sempre maiores do que o faturamento calculado com o preço das praças de referência, e as maiores diferenças se referem aos estados do Centro-Oeste: Mato Grosso e Mato Grosso do Sul; além da Bahia. Pelo teste de Wilcoxon, as diferenças entre o Faturamento (FAO) foram estatisticamente significativas ao nível de confiança de 5\%. Essa diferença se deve, 
em boa medida, pela distância entre a região produtora e a de formação de preço, que é o Porto de Paranaguá.

Vale destacar a importância de se desenhar contratos com variáveis que sejam mais representativas das regiões, como o preço do produto. Isso porque, a um preço menor, os contratos firmados poderiam ser avaliados em valores menores, com um custo menor para o produtor, o que poderia incentivá-lo a contratar o seguro faturamento. Adicionalmente, o contrato atual não especifica a fonte para obtenção do preço garantido no contrato, o que pode levar a um preço com nível inferior ao de Paranaguá, resultando em um contrato cujo gatilho de preço dificilmente será ativado.

Tabela 6 - FAO calculado a preços regionais e de referência e respectiva diferença entre os faturamentos calculados.

\begin{tabular}{cccc} 
Praça & $\begin{array}{c}\text { Faturamento Médio } \\
\text { (R\$ mi) }\end{array}$ & $\begin{array}{c}\text { Faturamento Médio } \\
\text { (R\$ mi - Preço } \\
\text { Paranaguá) }\end{array}$ & Diferença (\%) \\
Bahia & 4,76 & 5,45 & $14,59^{*}$ \\
Mato Grosso & 29,65 & 37,85 & $27,66^{*}$ \\
Mato Grosso do Sul & 8,21 & 9,39 & $14,39^{*}$ \\
Paraná & 21,2 & 22,91 & $8,07^{*}$ \\
Rio Grande do Sul & 21,64 & 23,54 & $8,78^{*}$ \\
São Paulo & 2,81 & 2,94 & $4,7 *$ \\
\hline
\end{tabular}

* Significativo a um nível de confiança de $95 \%$ pelo teste de Wilcoxon. Fonte: Calculado pelos autores a partir dos dados da pesquisa.

A Tabela 7 mostra o risco de preço, produção e faturamento, além das correlações entre preços e produção. É possível verificar que de fato o risco de produção é muito menor para os estados do Centro-Oeste do que o risco de preço. No caso de Mato Grosso, por exemplo, o risco de preço é cinco vezes maior do que o risco de produtividade. Já no caso do risco de faturamento, a diferença entre os estados é menor, sendo que este risco é maior para Bahia, São Paulo e Mato Grosso do Sul. Ainda, a correlação entre as séries de preço e produção e entre os preços regionais com o preço do porto, embora pequena, apresenta sinal contrário (negativo).

Tabela 7 - Risco relativo das variáveis preço, produção e faturamento e correlação entre as séries de preços.

\begin{tabular}{lccccc} 
& \multicolumn{2}{c}{ Coeficiente de variação (\%) } & \multicolumn{2}{c}{ Correlação (Tau de Kendall) } \\
\cline { 2 - 6 } Praça & Produção & Preço & Faturamento & $\begin{array}{c}\text { Preço x } \\
\text { Produção }\end{array}$ & $\begin{array}{c}\text { Preço x } \\
\text { Preço BM\&F }\end{array}$ \\
\hline Rio Grande do Sul & 14,03 & 12,9 & 13,29 & $-0,35^{*}$ & $-0,08^{*}$ \\
Paraná & 11,71 & 13,04 & 14,61 & $-0,14^{*}$ & $-0,07^{*}$ \\
Mato Grosso & 3,31 & 15,27 & 14,73 & $-0,18^{*}$ & $-0,13^{*}$ \\
Mato Grosso do Sul & 10,49 & 14,74 & 15,24 & $-0,16^{*}$ & $-0,03^{*}$ \\
São Paulo & 11,18 & 12,34 & 16,09 & $-0,02$ & $0,01^{*}$ \\
Bahia & 13,25 & 14,18 & 17,87 & $-0,13^{*}$ & $-0,13^{*}$ \\
BM\&F & - & 12,52 & - & - & - \\
\hline
\end{tabular}

*Significativo a um nível de confiança de 95\%. Fonte: Calculado pelos autores a partir dos dados da pesquisa. 
A Figura 3 detalha essa diferença para municípios produtores dos estados em estudo. Já a Tabela 8 mostra o valor das indenizações, em bilhões de reais, calculadas para os contratos de seguro de faturamento, a partir dos preços regionais e do preço de Paranaguá. Novamente, a diferença é maior no caso dos estados de Mato Grosso e Mato Grosso do Sul. Este fato pode ser um indicativo do motivo de os produtores desses estados não se sentirem atraídos pelo seguro agrícola na forma que estão desenhados atualmente, quando comparamos com a demanda dos produtores dos estados da região Sul.

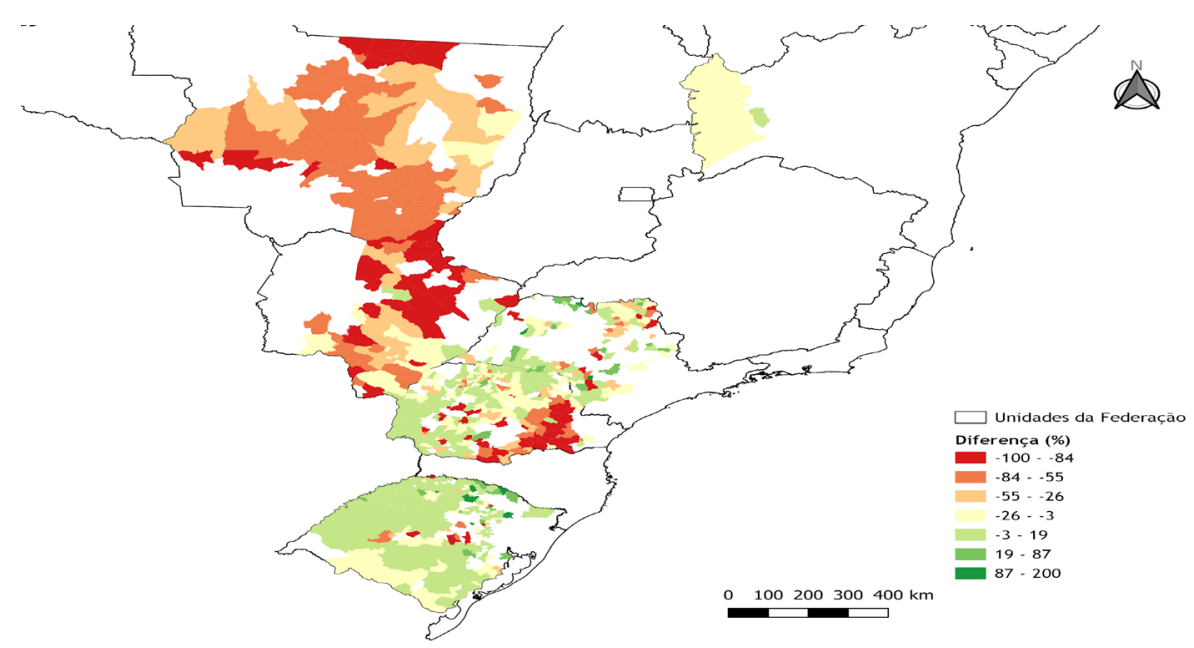

Figura 3 - Diferença, em termos percentuais, no montante indenizado pelo seguro faturamento baseado no índice da soja BM\&F e nos preços regionais entre os anos de 2008-2018. Fonte: Calculado pelos autores a partir dos dados da pesquisa.

Tabela 8 - Indenizações, em bilhões de reais, calculadas para os contratos de seguro de faturamento, a partir dos preços regionais e do preço de Paranaguá

\begin{tabular}{cccc} 
& \multicolumn{2}{c}{ Indenizações (R\$ bi) } & Diferença (\%) \\
\cline { 2 - 3 } BA & Preço regional & Preço Paranaguá/BM\&F & $-8,98$ \\
MS & 180,85 & 164,61 & $-50,51$ \\
MT & 89,46 & 44,28 & $-61,6$ \\
PR & 794,86 & 305,21 & $-3,62$ \\
RS & 240,41 & 231,70 & 3,72 \\
SP & 255,50 & 264,99 & $-2,08$ \\
\hline
\end{tabular}

Fonte: Elaborado pelos autores a partir dos dados da pesquisa

\section{CONCLUSÕES}

O seguro de faturamento é uma reivindicação relativamente antiga do setor agropecuário. Nesse sentido, em 2011 e 2012, algumas seguradoras incluíram em seu portfólio o seguro de faturamento e/ou receita. Nesse tipo de seguro, é oferecido ao produtor rural proteção contra a queda de seu faturamento, garantindo de forma conjunta preço e produtividade.

Há que se ressaltar que até o momento não existe legislação específica do órgão fiscalizador para o seguro de faturamento e/ou receita, no entanto, essas operações têm recebido apoio do 
Governo através dos recursos alocados ao PSR, em razão das frequentes solicitações realizadas pelos produtores rurais e pelas experiências de sucesso ocorridas em outros países em que o seguro de faturamento é oferecido.

Nos EUA, o seguro de faturamento é oferecido desde 1996, e atualmente é a cobertura de seguro mais comercializada entre os produtores norte-americanos. No Brasil, essa modalidade é relativamente nova. Nesse tipo de seguro, o desafio é definir, além da produtividade esperada, também o preço a ser garantido. Quando a projeção do preço e a produtividade esperada são bem definidos e aderentes às necessidades dos produtores rurais, o seguro torna-se atrativo.

Devido à dificuldade de se obter preços, municipais ou regionais, das principais praças de comercialização, as seguradoras têm utilizado no desenho desses produtos o preço de Paranaguá, que é referência para liquidação de contratos de derivativos agropecuários. No entanto, os resultados da pesquisa mostraram que o uso do preço regional pode melhorar sobremaneira o desenho dos produtos e torná-los mais atrativos para produtores de importantes estados produtores, por exemplo o estado do Mato Grosso.

Apesar das limitações encontradas, os resultados indicam importantes contribuições para o melhor entendimento do seguro de faturamento. De forma geral, os resultados da pesquisa mostraram que há fraca associação entre as séries de preço e produtividade, pois o efeito estimado ficou próximo de zero, mas tem caráter negativo em que preço e produção apresentam comportamento inversamente correlacionado.

Em particular, foi possível verificar que o risco de produção é menor nos estados do Centro-Oeste em relação ao risco de preço. Um exemplo é o estado do Mato Grosso, em que o risco de preço é cinco vezes maior do que o risco de produtividade. Já no caso do risco de faturamento, a diferença entre os estados é menor, sendo que este é maior para Bahia, São Paulo e Mato Grosso do Sul.

Destaca-se dessa forma a importância da escolha do parâmetro de preços como um fator de influência no cálculo da indenização. Em outras palavras, em caso de sinistro, ao utilizar o preço de Paranaguá, os produtores receberiam um montante de indenização menor caso utilizassem o preço de referência da sua região. Em particular, para os estados do Mato Grosso e Mato Grosso do Sul, a diferença poderia ser muito maior. Este fato pode ser um indício da baixa contratação do seguro de faturamento por esses produtores, mesmo com subvenção ao prêmio, quando comparamos com a demanda dos produtores dos estados da região Sul.

Para futuras pesquisas, sugere-se avançar nas análises utilizando-se dados de municípios e até mesmo de propriedades, caso estejam disponíveis, para melhor entender o comportamento da função faturamento e de modo a gerar informações que possam auxiliar a desenhar um seguro que seja atrativo tanto para a seguradora quanto para o produtor, o que ainda apresenta muitas discussões.

\section{REFERÊNCIAS}

Adami, A. C. O., \& Ozaki, V. A. (2016). Estudo sobre a viabilidade do Seguro Receita: o caso da região oeste do Paraná. Revista de Economia e Sociologia Rural, 54(2), 305-318.

Arias, D., Mendes, P., \& Abel, P. (2015). Revisão rápida e integrada da gestão de riscos agropecuários no Brasil: caminhos para uma visão integrada. Brasilia, DF: Banco Mundial.

Banco do Brasil. (2021). BB Seguro Agrícola Faturamento. Recuperado em 20 de abril de 2020, de https://www.bbseguros.com.br/seguradora/seguros/para-seus-negocios/seguroagronegocio/seguro-agricola-faturamento/

Brasil. Companhia Nacional de Abastecimento - CONAB. (2019). Acompanhamento da safra brasileira de grãos (Vol. 1, No. 2). CONAB. 
Brasil. Ministério da Agricultura, Pecuária e Abastecimento - MAPA. (2020a). Agronegócio brasileiro em números. Recuperado em 20 de abril de 2020, de http://www.slideshare. net/MinAgriculturaBrasil/agronegcio-brasileiro-em-nmeros

Brasil. Ministério da Agricultura, Pecuária e Abastecimento - MAPA. (2020b). Seguro rural: programa de subvenção ao prêmio do Seguro Rural. Recuperado em 20 de abril de 2020, de https://www.gov.br/agricultura/pt-br/assuntos/riscos-seguro/seguro-rural/documentosseguro-rural/copy_of_RelatorioGeralPSR2019.pdf

Brasil. Ministério da Agricultura, Pecuária e Abastecimento - MAPA. (2020c). Políticas agrícolas/ Seguro Rural. Recuperado em 15 de fevereiro de 2020, de http://www.agricultura.gov.br/

Brasil. Ministério da Agricultura, Pecuária e Abastecimento - MAPA. (2020d). Atlas do Seguro Rural. Recuperado em 16 de novembro de 2020, de http://indicadores.agricultura.gov.br/ atlasdoseguro/index.htm

Brisolara, C. S. (2013). Proposições para o desenvolvimento do seguro de receita agrícola no Brasil: do modelo teórico ao cálculo das taxas de prêmio (Doctoral dissertation). Universidade de São Paulo.

Duarte, G. V., Braga, A., Miquelluti, D. L., \& Ozaki, V. A. (2018). Modeling of soybean yield using symmetric, asymmetric and bimodal distributions: implications for crop insurance. Journal of Applied Statistics, 45(11), 1920-1937.

Duarte, G. V., \& Ozaki, V. A. (2019). Pricing Crop Revenue Insurance using Parametric Copulas. Revista Brasileira de Economia, 73(3), 325-343.

Enders, W. (2008). Applied econometric time series. John Wiley \& Sons.

Food and Agriculture Organization of the United Nations - FAO (2020). FAO corporate statistical database. Recuperado em 27 de fevereiro de 2020, de http://faostat.fao.org/default.asp

Gallagher, P. (1987). US soybean yields: estimation and forecasting with nonsymmetric disturbances. American Journal of Agricultural Economics, 69(4), 796-803.

Ikeda, V. Y. (2015). Integração entre os mercados de soja de Paranaguá (PR) e Sorriso (MT): impacto da nova rota de exportação pelo Porto de Santarém (PA) (Doctoral dissertation). Universidade de São Paulo.

Instituto Brasileiro de Geografia e Estatística - IBGE. (2020). Levantamento sistemático da produção agrícola - LSPA. Recuperado em 12 de fevereiro de 2020, de http://www.ibge. gov.br/home/estatistica/indicadores/agropecuaria/lspa/

Mafioletti, R. L. (2001). Formação de preços na cadeia agroindustrial da soja na década de 90. Revista de Economia e Sociologia Rural, 39(4), 9-26.

Margarido, M. A., Turolla, F. A., \& Fernandes, J. M. (2001). Análise da elasticidade de transmissão de preços no mercado internacional da soja. Pesquisa e Debate, 12(2(20)), 5-40.

Miqueleto, G. J. (2011). Contribuições para o desenvolvimento do seguro agrícola de renda para o Brasil: evidências teóricas e empíricas (Doctoral dissertation). Universidade de São Paulo.

Mood, A. M., Graybill, F. A., \& Boes, D. C. (1974). Introduction to the theory of statistics. McGrawHill Kogakusha.

Moraes, M. D. (2002). Prêmio de exportação da soja brasileira (Doctoral dissertation). Universidade de São Paulo.

Ozaki, V. (2010). Uma digressão sobre o Programa de Subvenção ao Prêmio do Seguro Rural e as implicações para o futuro deste mercado. Revista de Economia e Sociologia Rural, 48(4), 495-514. 
Presotto, E., Freitas, C., Lazaretti, L., \& Feistel, P. (2019). Análise da transmissão do preço pago ao produtor de soja brasileiro (1997 a 2016). Perspectiva Econômica, 14(2). https://doi. org/10.4013/pe.2018.142.03

Sousa, E. D., \& Margarido, M. (1998). Formação de preços da soja no Brasil. In XXXIV Congresso da Sociedade Brasileira de Economia, Administração e Sociologia Rural(pp. 45-61). São Paulo.

United States Department of Agriculture - USDA. Risk Management Agency - RMA. (2020). Recuperado em 27 de março de 2020, de https://www.rma.usda.gov/SummaryOfBusiness

Universidade de São Paulo - USP. Centro de Estudos Avançados em Economia Aplicada - CEPEA. (2020). Preços Agropecuários. Recuperado em 25 de março de 2016, de http://www.cepea. esalq.usp.br/

Waquil, P. D., \& Dalla Libera, A. A. (2009). Transmissão de preços entre os mercados de soja. Revista de Política Agrícola, 18(3), 58-69. 